\title{
BAD POLICIES UNDER AN AUTOCRAT'S PRODUCTION
}

\author{
Byeongju Jeong* \\ CERGE-EI \\ POB 882, Politickych veznu 7 \\ 11121 Prague 1 \\ Czech Republic \\ email: byeongju.jeong@cerge.cuni.cz
}

October 2000

\begin{abstract}
Bad policies (i.e., policies harmful to private producers such as excessive taxation, arbitrary confiscation, and negligence of pubic goods) are observed in quite a few countries. These countries tend to have autocratic regimes. I explore a reason why bad policies may benefit autocrats. I present a model economy where the autocrat manages his production (e.g., military exploits, plantation cultivation, mining) in addition to setting policies for the private producers. The autocrat has an incentive to repress the income level of private producers: it reduces the wage rate that he must offer to his workers and thereby increases the surplus from his production. Thus the autocrat chooses a tax rate that is higher than the revenue-maximizing rate: it lies on the backward-bending part of the Laffer curve. He may also choose to lower the productivity of private producers through confiscation, neglect of public goods, and other non-tax policies. I argue that the story is helpful in understanding bad policies present in militaristic regimes of the Ottoman and Mughal empires, Trujillo's regime in the plantation-based economy of the Dominican Republic, and Mobutu's regime in mineral-rich Zaire.
\end{abstract}

JEL classification: E62; H21; N40

Keywords: autocracy; policy; tax

* I thank Radim Bohacek, Michal Kejak, and seminar participants at CERGE-EI, Central European University, and the European Public Choice Society Meeting for helpful comments. 


\section{INTRODUCTION}

In various countries, both historical and contemporary, we can observe government policies that are clearly harmful to private producers (in short, 'bad policies' from now on). Examples of bad policies include excessive taxation, arbitrary confiscation, and complete negligence of public goods such as public roads. Countries with bad policies tend to have autocratic regimes. The Ottoman and Mughal empires, the Dominican Republic under Trujillo, and Zaire under Mobutu, all of which will be discussed later, are some of the countries that were ruled by autocrats who implemented bad policies. Among the possible reasons why these autocrats implemented bad policies, in this paper I explore one reason that stems from the conditions for the autocrat's own production.

Before getting into the story of the paper, I will discuss some of the more well-known reasons for autocrats choosing bad policies. First of all, we would need a selfish autocrat. If the autocrat only cares about his own welfare, policies that are bad to others can be good for him. A higher tax rate is bad for the taxed but may bring in more revenue for the ruler. Confiscation and neglect of public goods may be understood in similar terms: confiscation brings in revenue and provision of public goods is costly. However, even an own-income-maximizing autocrat would restrain himself not to over-tax or under-provide. High tax rates or arbitrary confiscation can reduce the tax revenue by reducing the tax base and some provision of basic public goods can do the opposite. The case for bad policies becomes stronger if the autocrat's tenure is short: less excessive policies may increase the

revenue in time but the increase would accrue only to his successor, whom he does not care about (Buchanan and Lee 1982). Another complication is the problem of time-consistency. The autocrat may promise moderate policies in the future to increase the tax base, but it may be in his interests to break his promise once the tax base increases, thus making his promise incredible. This problem of time-consistency would diminish if the autocrat's tenure is longer since then he can build reputation as a moderate policy maker. In short, a 
selfish autocrat who takes his short tenure as given may very well explain many instances of bad policies.

In many other instances of bad policies, the autocrat enjoyed a long tenure, spanning over decades, and appear to have been secure in power. In these instances, the problem of time-consistency is mitigated and the autocrat can optimize over the long horizon. Reading about these instances, I get the impression that the selfishness of the autocrat by itself may not be enough a reason for the observed bad policies, and we need some other corroborating reasons. One corroborating reason may be that bad policies are somehow good for prolonging tenure. For example, Robinson (1997b) holds that under-provision of public good makes rebellion more difficult and thus prolongs the ruler's tenure. This reasoning seems plausible and is supported by evidence. In this paper I explore another possible reason for implementation of bad policies by a selfish autocrat with long tenure, abstracting from the issue of maintaining power.

The basic story is as follows. Imagine a selfish autocrat who taxes private producers and engages in his own production using hired workers. The difference between the private production and the autocrat's production is that the former is more difficult to supervise than the latter, so the autocrat would choose to tax the former and manage the latter. The private production may be peasant farming, commerce, or manufacturing industries. The autocrat's production may be military exploits, plantation production, or mining industries. In recruiting his workers, the autocrat must offer wage rate for his workers that is equal to the private producer's net-of-tax income. Then, the autocrat's choice of the tax rate not only affects the tax revenue, but it also affects the wage rate of the autocrat's workers. By increasing the tax rate, the autocrat can reduce the wage rate and thereby increase the surplus from his own production. Due to this reason, the autocrat chooses a tax rate that is greater than the revenue-maximizing rate: it lies on the backwardbending part of the Laffer curve. Further, an autocrat with greater productivity of his 
own production has more incentive to reduce the wage rate, and thus chooses a higher tax rate.

In Section 2, I present a model economy with these features. In Section 3, I extend the basic story and characterize the autocrat's preference for non-tax policies. The autocrat may want to repress the productivity of private producers by such means as extortion, confiscation, and under-provision of public goods. Again, an autocrat with greater productivity of his own production has more incentive to repress the productivity of private producers. The story in Sections 2 and 3 most readily apply to autocratic regimes that have great opportunities for and capability of own production. In Section 4, I argue that this story is helpful in understanding the bad policies that were present in the militaristic regimes of the Ottoman and Mughal empires, Trujillo's regime in the plantation-based economy of the Dominican Republic, and Mobutu's regime in mineral-rich Zaire. In Section 5, I summarize the results of the paper and conclude.

\section{Taxation under Autocrat's Production}

Consider the following economy. There are an autocrat and measure one of subjects who are ex-ante identical. Every subject has one unit of labor endowment, and using this labor he can either produce output on his own or work for the autocrat. If a subject engages in own-production, he allocates his labor between the formal sector and the informal sector. The difference between the two sectors is that the formal-sector output is taxed and the informal-sector output is not taxed. Let $l$ denote the labor allocated to the formal-sector production. The subject-producer's total output is given by

$$
y_{p}=f(l)+h(1-l)
$$

In this equation, $f(l)$ is the formal-sector output and $h(1-l)$ is the informal-sector output. Let $\psi(l) \equiv f^{\prime}(l) / h^{\prime}(1-l)$ and assume that $\psi(0)>1, \psi^{\prime}(l)<0$ for all $l$, and $\psi(1) \leq 0$. This means that the formal-sector labor is more productive than the informal-sector labor when 
$l=0$ but this relative productivity advantage of the formal-sector production decreases as $l$ increases, and disappears when or before $l$ reaches 1 . The first and the last part of the assumption insure that the equilibrium labor allocation is interior. Let $\tau$ denote the $\operatorname{tax}$ rate and $z$ the tax revenue from one producer:

$$
z=\tau f(l) .
$$

The subject-producer's utility is his output net of taxes:

$$
u_{p}=y_{p}-z
$$

If a subject works for the autocrat, he allocates all his labor to this activity. Let $w$ denote the wage rate for the autocrat's worker. The subject-worker's utility is his wage:

$$
u_{e}=w
$$

Let $n$ denote the number of subject-workers. ( $1-n$ is then the number of subjectproducers.) The autocrat produces output using the labor of his workers. This output is given by

$$
y_{a}=g(n) .
$$

Let $\grave{y}_{p} \equiv \min _{l}\left(y_{p}\right)$ and $\grave{y}_{p} \equiv \max _{l}\left(y_{p}\right)$, and assume that $g^{\prime}(0)>\grave{y}_{p}, g^{\prime}(n)$ is decreasing in $n$, and $g^{\prime}(1)<\dot{y}_{p}$. The first and the last parts of the assumption insure that the equilibrium number of workers is interior. The autocrat's utility is the tax revenue plus his output net of wage payment:

$$
u_{a}=z(1-n)+y_{a}-w n
$$

The first event in this economy is for the autocrat to recruit workers. The recruitment takes place in a market where the autocrat behaves as a monopsony and the subjects behave competitively. The second event is production: each subject-producer produces his own output, dividing labor between the two sectors, and the subject-worker produces output 
for the autocrat. The final event is for the autocrat to collect taxes from subject-producers and to pay wages to subject-workers.

It is useful to describe the decision problems of the autocrat and the subjects in reverse order. In the production stage, each subject-producer chooses the formal-sector labor $l$ to maximize $u_{p}$, taking $\tau$ as given. Note that all subject-producers are identical, so their labor allocation choice is the same. Let $\tilde{l}(\tau)$ be the individual labor supply schedule for the formal setor: a subject-producer's labor allocated to the formal sector is given by

$$
l=\tilde{l}(\tau)
$$

In the recruitment stage, each subject chooses between the two occupations, the producer and the worker, comparing $u_{p}$ and $u_{s}$ and taking $\tau$ and $w$ as given. Let $\tilde{n}(\tau, w)$ denote the aggregate supply schedule of workers: the number of workers is given by

$$
n=\tilde{n}(\tau, w) .
$$

The autocrat chooses $\tau, w$, and $n$ to maximize $u_{a}$, taking $\tilde{l}(\tau)$ and $\tilde{n}(\tau, w)$ as given. An equilibrium of this economy is the tax rate $\tau$, the wage rate $w$, the number of workers $n$ that solve the autocrat's problem, and the formal-sector labor $l$ that solves the subjectproducer's problem given $\tau$.

To characterize the equilibrium, it is again useful to consider the behavior of the autocrat and subjects in reverse order. Let us first consider the subject-producer's behavior under varying tax rates. Given the assumed properties of $f$ and $h$, we have the following proposition regarding the subject-producer's labor allocation choice.

Proposition 1. There is a cut-off tax rate $\bar{\tau}>0$ such that $\tilde{l}(0)>0, \tilde{l}(\tau)$ is decreasing while $0<\tau<\bar{\tau}$, and $\tilde{l}(\tau)=0$ for $\tau \geq \bar{\tau}$.

Proof: Given the monotonicity of $\psi$, from $(1),(2)$, and (3), the first-order condition for the producer's problem is, for any $\tau,(1-\tau) \psi(\tilde{l}(\tau)) \leq 1$ if $\tilde{l}(\tau)=0,(1-\tau) \psi(\tilde{l}(\tau))=1$ if 
$0<\tilde{l}(\tau)<1$, and $(1-\tau) \psi(\tilde{l}(\tau)) \geq 1$ if $\tilde{l}(\tau)=1$. Given that $\psi(0)>0$ and $\psi(1) \leq 1$, from the first-order condition, we can show that $\tilde{l}(0)>0$ and $\psi(\tilde{l}(0))=1$. Then, there is $\bar{\tau}>0$ that satisfies $(1-\bar{\tau}) \psi(0)=1$. If $0<\tau<\bar{\tau},(1-\tau) \psi(1)<\psi(1) \leq 1$ and $(1-\tau) \psi(0)>(1-\bar{\tau}) \psi(0)=1$ so that $(1-\tau) \psi(\tilde{l}(\tau))=1$. Then, $\tilde{l}(\tau)$ is decreasing while $0<\tau<\bar{\tau}$. If $\bar{\tau} \leq \tau \leq 1, \tilde{l}(\tau)=0$ since otherwise $(1-\tau) \psi(\tilde{l}(\tau))<(1-\bar{\tau}) \psi(0)=1$, violating the first-order condition. Q.E.D.

Intuitively, the formal-sector labor will be the greatest when $\tau=0$. As $\tau$ increases from 0 , the formal-sector labor decreases and the informal-sector labor increases since the net-oftax return from formal-sector production (relative to informal-sector production) decreases. If $\tau$ is high enough, labor is entirely allocated to the informal sector since the relative return advantage of formal-sector production disappears. We can show that as $\tau$ increases from 0 to $\bar{\tau}$, the output $y$ decreases. This is because a higher tax rate shifts the labor from the more productive formal-sector production to the less productive informal-sector production. We can also show that as $\tau$ increases from 0 to $\bar{\tau}$, the subject-producer's utility $u_{p}$ decreases. To see this, note that a lower tax rate can only make the subject-producer better off because even without changing his labor allocation choice, his utility would increase due to the lower taxes.

Let us now consider the behavior of the autocrat and the subjects in the recruitment market. Each subject's occupational choice is simple: choose whichever occupation delivers greater utility. The tax rate $\tau$ determines the producer's utility and the wage rate $w$ determines the worker's utility. Thus each subject's occupational preference is determined by $\tau$ and $w$. Since all subjects are ex-ante identical, their occupational preference is the same. Then, given $\tau$ and $w$, the supply schedule of employees $\tilde{n}(\tau, w)=0$ if $u_{p}>u_{s}$, $\tilde{n}(\tau, w)=1$ if $u_{p}<u_{s}$, and $\tilde{n}(\tau, w)$ can be any value from 0 to 1 if $u_{p}=u_{s}$. Now let us think about the autocrat's problem of choosing $\tau, w$, and $n$ in two steps: first choosing $\tau$, and next choosing $w$ and $n$ given $\tau$. Considering these steps backwards, note that given $\tau$, the subject-producer's utility $u_{p}$ is fixed. To recruit any workers, the autocrat must offer 
$w$ high enough so that the subjects are willing to be workers (i.e., $u_{p} \leq u_{s}$ ). On the other hand, he will choose a $w$ that is the lowest among these acceptable $w$ 's since his utility is greater with less wage payment. Thus he will offer $w$ so that the subjects are indifferent between becoming producers and becoming workers:

$$
u_{p}=u_{s}
$$

Using (3), (4), and (9), we can rewrite the autocrat's utility in (6) as

$$
u_{a}=z+y_{a}-y_{p} n
$$

The first-order condition for $n$ in this equation is

$$
g^{\prime}(n)=y_{p}
$$

Intuitively, in choosing $n$, the autocrat equates the marginal product from hiring an additional worker to the marginal cost of hiring that additional worker. The marginal cost is the sum of the wage rate and the loss of the tax revenue from losing one producer, and this sum is equal to one producer's output. The autocrat's problem is then reduced to choosing $\tau$ given that $w$ and $n$ are determined by (9) and (10).

Now, we can see from $(6)^{\prime}$ and (10) that, in choosing $\tau$, the autocrat has to consider the effects of the tax rate on the tax revenue $z$ and on $y_{p}$. In characterizing the autocrat's choice of tax rate, it is convenient to have the tax revenue exhibit the Laffer curve. To this end, for the remainder of the analysis, assume that $f^{\prime}(l) / \psi^{\prime}(l)$ is non-decreasing in $l$. This basically means that $f$ and/or $\psi$ have some concavity.

Proposition 2. The tax revenue $z$ exhibits a Laffer curve: $z=0$ if $\tau=0$ or $\bar{\tau} \leq \tau \leq 1$, and there is a unique tax rate $\check{\tau}$, where $0<\check{\tau}<\bar{\tau}$, so that as $\tau$ increases, $z$ increases while $0<\tau<\check{\tau}$ and decreases while $\check{\tau}<\tau<\bar{\tau}$. 
Proof: For $\tau=0, z=0$ from (2). For $\tau \in[\bar{\tau}, 1], \tilde{l}(\tau)=0$ so that $z=0$. For $l \in[0, \bar{\tau})$, using $(1-\tau) \psi(\tilde{l}(\tau))=1$ from the proof of Proposition 1, we have $\tilde{l}^{\prime}(\tau)=1 /\left[(1-\tau)^{2} \psi^{\prime}(\tilde{l}(\tau))\right]$. Given this, we can show $d z / d \tau=f(\tilde{l}(\tau))+\tau f^{\prime}(\tilde{l}(\tau)) /\left[(1-\tau)^{2} \psi^{\prime}(\tilde{l}(\tau))\right]$. Then, if $\tau=0$, $d z / d \tau=f(\tilde{l}(0))>0$; Since $f^{\prime}(l) / \psi^{\prime}(l)$ is non-decreasing and $\tilde{l}(\tau)$ is decreasing (Proposition $1), d z / d \tau$ is decreasing while $0 \leq \tau<\bar{\tau}$; and as $\tau \rightarrow \bar{\tau}, d z / d \tau \rightarrow f(0)+\tau f^{\prime}(0) /[(1-$ $\left.\tau)^{2} \psi^{\prime}(0)\right]<0$. From this, it follows that there is $\check{\tau}$ characterized as in the proposition. Q.E.D.

If the tax revenue was the only concern for the autocrat, then he would choose the revenuemaximizing tax rate $\check{\tau}$. However, the tax rate not only determines the tax revenue but also the producer's output $y_{p}$, and this determines the costs of employing a worker. As for this latter effect of the tax rate, the higher the tax rate, the better off the autocrat is: a higher $\tau$ reduces the producer's output $y_{p}$, a lower $y_{p}$ implies a lower cost of employing a worker, and this increases the autocrat's surplus from his own production (see equations $6^{\prime}$ and 10). The following proposition characterizes the effect of this autocrat's concern for lower employment costs on the equilibrium tax rate.

Proposition 3. Any equilibrium tax rates lie on the backward-bending part of the Laffer curve and further, any equilibria are interior: for any given equilibrium elements $\hat{\tau}, \hat{n}$, and $\hat{l}, \check{\tau}<\hat{\tau}<\bar{\tau} ; 0<\hat{n}<1 ;$ and $0<\hat{l}<1$.

Proof: Let $\hat{\tau}, \hat{n}, \hat{l}$ be a set of equilibrium elements. Since $g^{\prime}(0)>\max _{l}\left(y_{p}\right)$ and $g^{\prime}(1)<$ $\min _{l}\left(y_{p}\right)$, from (10), we have $g^{\prime}(1)<g^{\prime}(\hat{n})<g^{\prime}(0)$ so that $0<\hat{n}<1$. Consulting the proof of Proposition 1, we can show that $\tilde{l}(\tau)$ is continuous so that $y_{p}$ and $z$ change continuously as $\tau$ changes. Then, given $\hat{n}$, in $(6)^{\prime}, u_{a}$ changes continuously as $\tau$ changes. For $\tau \in[0, \bar{\tau})$ and $\tau \in(\bar{\tau}, 1], d z / d \tau$ and $d y_{p} / d \tau$ are well defined, so we can write $\partial u_{p} / \partial \tau=d z / d \tau-$ $\left(d y_{p} / d \tau\right) \hat{n}$. To characterize $\partial u_{p} / \partial \tau$, consider $\tau$ 's in three segments. First, for $\tau \in[0, \tilde{\tau}]$, we have $d z / d \tau \geq 0$ from Proposition 2, and we can show $d y_{p} / d \tau<0$ so that $\partial u_{p} / \partial \tau>0$. Next, for $\tau \in(\check{\tau}, \bar{\tau})$, we can derive $\partial u_{p} / \partial \tau=f(\tilde{l}(\tau))+\tau(1-\hat{n}) f^{\prime}(\tilde{l}(\tau)) /\left[(1-\tau)^{2} \psi^{\prime}(\tilde{l}(\tau))\right]$. Since $f^{\prime}(l) / \psi^{\prime}(l)$ is non-decreasing and $\tilde{l}$ is decreasing, $\partial u_{p} / \partial \tau$ is decreasing, and as $\tau \rightarrow \bar{\tau}$, $\partial u_{p} / \partial \tau \rightarrow \tau(1-\hat{n}) f^{\prime}(0) /\left[(1-\tau)^{2} \psi^{\prime}(0)\right]<0$. Finally, for $\tau \in(\bar{\tau}, 1], d z / d \tau=0$ and $d y_{p} / d \tau=0$ so that $\partial u_{p} / \partial \tau=0$. From this characterization of $\partial u_{p} / \partial \tau$, it follows that $\check{\tau}<\hat{\tau}<\bar{\tau}$. Then, from Proposition 1, we have $0<\hat{l}<1$. Q.E.D. 
Thus the autocrat's concern for recruitment makes him choose a higher tax rate than the revenue-maximizing one.

In this model, depending on the properties of the production functions $f, g$, and $h$, there can be more than one equilibria. To simplify the remainder of the analysis, I will make a further assumption on the production functions to ensure that there is a unique equilibrium. Let $\xi\left(y_{a}\right)$ be the inverse function of $g^{\prime}(n)$ and assume that $\xi^{\prime}\left(y_{a}\right) \geq$ $\left[(1-\bar{\tau})^{2} \psi^{\prime}(0)\right] /\left[\bar{\tau}^{2} f^{\prime}(0)\right]$ for all $y_{a} \in\left[\hat{y}_{p}, \grave{y}_{p}\right]$. This basically means that $g$ is concave enough.

Proposition 4. There is a unique equilibrium.

Proof: From Proposition 3, any equilibrium tax rates are in $(\check{\tau}, \bar{\tau})$. In the following, all the statements are for $\tau \in(\check{\tau}, \bar{\tau})$. In the proof of Proposition 2, we saw that $y_{p}$ and $z$ change continuously as $\tau$ changes. From (5) and (10), $n$ and $y_{a}$ also change continuously as $\tau$ changes. Then, in $(6)^{\prime}, u_{a}$ changes continuously as $\tau$ changes. Let $\tilde{y}_{p}(\tau) \equiv f(\tilde{l}(\tau))+h(1-\tilde{l}(\tau))$. From $(6)^{\prime}$, using (5) and (10), we can derive $d u_{a} / d \tau=$ $d z / d \tau-\tilde{y}_{p}^{\prime}(\tau) \xi\left(\tilde{y}_{p}(\tau)\right)=f(\tilde{l}(\tau))+\left(1-\xi\left(\tilde{y}_{p}(\tau)\right)\right)\left(\tau f^{\prime}(\tilde{l}(\tau))\right) /\left((1-\tau)^{2} \psi^{\prime}(\tilde{l}(\tau))\right)$. Consulting the proof of Proposition 3, we can show that as $\tau \rightarrow \check{\tau}$, $d u_{a} / d \tau>0$, and as $\tau \rightarrow \bar{\tau}, d u_{a} / d \tau<0$. Since $f^{\prime}(l) / \psi^{\prime}(l)$ is non-decreasing and $\tilde{l}$ is decreasing, the expression $\left(\tau f^{\prime}(\tilde{l}(\tau))\right) /\left((1-\tau)^{2} \psi^{\prime}(\tilde{l}(\tau))\right)$ is decreasing in $\tau$. Given this, $d u_{a} / d \tau$ is decreasing if $d f(\tilde{l}(\tau)) / d \tau-\left(d \xi\left(\tilde{y}_{p}(\tau)\right) / d \tau\right)\left(\tau f^{\prime}(\tilde{l}(\tau))\right) /\left((1-\tau)^{2} \psi^{\prime}(\tilde{l}(\tau))\right) \leq 0$. We can show that this inequality holds, using that $\xi^{\prime}\left(y_{a}\right) \geq\left[(1-\bar{\tau})^{2} \psi^{\prime}(0)\right] /\left[\bar{\tau}^{2} f^{\prime}(0)\right]$ for all $y_{a} \in\left[y_{p}, \grave{y}_{P}\right]$. Thus $d u_{a} / d \tau$ is decreasing. It follows that there is a unique equilibrium tax rate, which implies the uniqueness of the values of all the other equilibrium elements. Q.E.D.

Given the uniqueness of the equilibrium, now we can further characterize the effect of the recruitment need on the tax rate. The following proposition states that the more productive the government production is, the autocrat chooses the higher tax rate and recruits the more workers.

Proposition 5. Given $f$ and $h$, let $g_{1}$ and $g_{2}$ be two government production functions, where $g_{1}^{\prime}(n)<g_{2}^{\prime}(n)$ for all $n$. Let $\hat{\tau}_{1}$ and $\hat{n}_{1}$ be the equilibrium tax rate and number of employees under $g_{1}$, and $\hat{\tau}_{2}$ and $\hat{n}_{2}$ those under $g_{2}$. Then, $\hat{\tau}_{1}<\hat{\tau}_{2}$ and $\hat{n}_{1}<\hat{n}_{2}$. 
Proof: Let $\xi_{1}$ and $\xi_{2}$ be the inverse functions of $g_{1}^{\prime}$ and $g_{2}^{\prime}$, respectively. Since $g_{1}^{\prime}(n)<$ $g_{2}^{\prime}(n)$ for all $n, \xi_{1}\left(y_{p}\right)<\xi_{2}\left(y_{p}\right)$ for all $y_{p}$. From the Proposition 4 , under $g_{i}, i=1,2$, $d u_{a} / d \tau=d z / d \tau+\tilde{y}_{p}^{\prime}(\tau) \xi_{i}\left(\tilde{y}_{p}(\tau)\right)$ for all $\tau \in(\check{\tau}, \bar{\tau})$. Then, $d u_{a} / d \tau$ under $g_{1}$ is smaller than $d u_{a} / d \tau$ under $g_{2}$ for all $\tau \in(\check{\tau}, \bar{\tau})$ so that $\hat{\tau}_{1}<\hat{\tau}_{2}$. Since $\tilde{y}_{p}^{\prime}(\tau)<0$ for all $\tau \in(\check{\tau}, \bar{\tau})$, we have $\tilde{y}_{p}\left(\hat{\tau}_{1}\right)>\tilde{y}_{p}\left(\hat{\tau}_{2}\right)$. Given this and using that $g_{1}^{\prime}(n)<g_{2}^{\prime}(n)$ for all $n$, from (10), we have $\hat{n}_{1}<\hat{n}_{2}$. Q.E.D.

Intuitively, if the autocrat's production is more productive, the autocrat would hire more workers. With a greater number of workers, the effect of a higher tax rate in reducing the wage payment becomes greater. On the other hand, with a lower number of producers, the effect of a higher tax rate on raising tax revenue becomes smaller. Therefore, the autocrat chooses a higher tax rate if his production is more productive.

\section{Non-Tax Policies under an Autocrat's Production}

The basic idea of the model in Section 2 is that under an autocrat's production, a lower income level of the population benefits the autocrat by saving the autocrat on the costs of employing his workers. Thus a higher tax rate benefits the autocrat by reducing the income level of the population. This effect of a higher tax rate is balanced against its effect on tax revenue, limiting the extent to which the autocrat raises the rate. The reasoning can be extended beyond the tax policy since in general non-tax policies would affect the income level of the population and the tax revenue. To elaborate, suppose that the autocrat has to choose between two sets of policies, A and B, where the policies can be about any aspects of the economy. If A and B yield similar amounts of tax revenue but A leads to a lower income level than $\mathrm{B}$, the autocrat will choose $\mathrm{A}$.

To make this point analytically, let us consider the following extension of the model in Section 2. In addition to taxation, now the autocrat can choose non-tax policies which affect the productivity of the producer. Let $\theta>0$ be the summary measure of non-tax policies. Given $f$ and $h$, if the autocrat chooses $\theta$, the effective production functions of the 
producer become $\theta f(l)$ and $\theta h(l)$ for all $l$. That non-tax policies affect the productivity of the informal sector as well as that of the formal sector is important for the results. This is a rough assumption but seems reasonable for a variety of policies. For example, the provision of public goods such as roads and basic education would affect the productivity of both formal and informal sectors. The autocrat would choose $\theta$ weighing the benefits and costs of choosing its various values. Among the costs would be the direct costs of implementing policies (e.g., the costs of building or destroying roads). These direct costs can be considered separately from those that operate through the productivity of producers. To consider non-tax policies insofar as they relate to the model in Section 2, I will not specify these direct costs and only consider the autocrat's policy preference in terms of the effects of non-tax policies through the productivity of producers.

The definition of equilibrium is as in Section 2, albeit the equilibrium now depends on $\theta$ : in all equations, $\theta f$ and $\theta g$ are substituted for $f$ and $g$. To insure the uniqueness of equilibrium given any $\theta$, we now need a somewhat stronger concavity assumption on $g$ than on page 9. For the remainder of the analysis, assume that $\xi^{\prime}\left(y_{a}\right) \geq$ $\left[(1-\bar{\tau})^{2} \psi^{\prime}(0) h(1)\right] /\left[\bar{\tau}^{2} f^{\prime}(0) y_{a}\right]$ for all $y_{a} \in[g(1), g(0)]$. The following proposition characterizes the autocrat's policy preference.

Proposition 6. Given $f, g$, and $h$, there is a cut-off $\bar{\theta}>0$ so that as $\theta$ increases, the equilibrium utility of autocrat $\hat{u}_{a}$ decreases while $\theta<\bar{\theta}$ and increases while $\theta>\bar{\theta}$.

Proof: Let all variables with hats denote the equilibrium values, determined given $\theta$. Consulting the proof of Proposition 4, we have that in $(6)^{\prime}$, given $\theta, u_{a}$ changes continuously as $\tau$ changes. Conversely, given $\tau$ and thereby fixing $l$ and $n, u_{a}$ changes continuously as $\theta$ changes. Further, the choice set of $\tau,[0,1]$, is compact. Then, by the Theorem of Maximum, $\hat{u}_{a}$ changes continuously as $\theta$ changes. Since $g^{\prime}(1)<\grave{y}_{p}<\grave{y}_{p}<g^{\prime}(0)$, there are $\theta_{1}<1$ and $\theta_{2}>1$ that satisfy $\theta_{1} \underline{y}_{p}=g^{\prime}(1)$ and $\theta_{2} \bar{y}_{p}=g^{\prime}(0)$.

To characterize $d \hat{u}_{a} / d \theta$, first consider the range $\left(0, \theta_{1}\right)$. Fix $\theta<\theta_{1}$. There is $\tau \leq \bar{\tau}$ such that $\theta \tilde{y}_{p}(\tau)>g^{\prime}(1)$ for $\tau<\dot{\tau}$ and $\theta \tilde{y}_{p}(\tau) \leq g^{\prime}(1)$ for $\tau \geq \dot{\tau}$, where $\tilde{y}_{p}$ is as defined in the proof of Proposition 4. Consulting the proof of Proposition 4, we can show that for $\tau \in$ 
$(\check{\tau}, \dot{\tau}), d u_{a} / d \tau=\theta f(\tilde{l}(\tau))+\left(1-\xi\left(\tilde{y}_{p}(\tau)\right)\right)\left(\tau \theta f^{\prime}(\tilde{l}(\tau))\right) /\left((1-\tau)^{2} \psi^{\prime}(\tilde{l}(\tau))\right)$, and that $d u_{a} / d \tau$ is decreasing given that $\xi^{\prime}\left(y_{a}\right) \geq\left[(1-\bar{\tau})^{2} \psi^{\prime}(0) h(1)\right] /\left[\bar{\tau}^{2} f^{\prime}(0) y_{a}\right]$ for all $y_{a} \in[g(1), g(0)]$. Further, as $\tau \rightarrow \dot{\tau}, \xi\left(\theta \tilde{y}_{p}(\tau)\right) \rightarrow 1$ so that $d u_{a} / d \tau \rightarrow \theta f(\tilde{l}(\tau)) \geq 0$. Thus, $d u_{a} / d \tau>0$ for all $\tau<\dot{\tau}$. For $\tau \in(\dot{\tau}, \bar{\tau})$, we have $\xi\left(\theta \tilde{y}_{p}(\tau)\right) \geq 1$ so that $d u_{a} / d \tau=d z / d \tau-\theta \tilde{y}_{p}^{\prime}(\tau)=$ $\theta f(\tilde{l}(\tau))>0$. Since $u_{a}$ changes continuously as $\tau$ changes, the above properties of $d u_{a} / d \tau$ imply that $\hat{\tau}=\bar{\tau}$ and, consequently, $\hat{n}=1$. We have shown that for all $\theta \in\left(0, \theta_{1}\right), \hat{\tau}=\bar{\tau}$ and $\hat{n}=1$. Then, from $(6)^{\prime}$, we have $d \hat{u}_{a} / d \theta=-\tilde{y}_{p}(\bar{\tau})<0$ for all $\theta \in\left[0, \theta_{1}\right)$.

Next, consider the range $\left(\theta_{1}, \theta_{2}\right)$. For any given $\theta \in\left(\theta_{2}, \theta_{2}\right), \theta \dot{y}_{p}>g^{\prime}(1)$ and $\theta \grave{y}_{p}<$ $g^{\prime}(0)$ so that Propositions 3 and 4 are valid. In particular, $\check{\tau}<\hat{\tau}<\bar{\tau}$ and at $\tau=\hat{\tau}$, $d u_{a} / d \tau=\theta f(\tilde{l}(\hat{\tau}))+\left(1-\xi\left(\theta \tilde{y}_{p}(\hat{\tau})\right)\right)\left(\hat{\tau} \theta f^{\prime}(\tilde{l}(\hat{\tau}))\right) /\left((1-\hat{\tau})^{2} \psi^{\prime}(\tilde{l}(\hat{\tau}))\right)=0$. Since this is true for all $\theta \in\left(\theta_{1}, \theta_{2}\right), \xi^{\prime}<0$, and $\psi^{\prime}<0$, we can show that $\hat{\tau} \rightarrow \bar{\tau}$ as $\theta \rightarrow \theta_{1} ; d \hat{\tau} / d \theta<0$; and $\hat{\tau} \rightarrow \check{\tau}$ as $\theta \rightarrow \theta_{2}$. Now, we have $d \hat{u}_{a} / d \theta=\partial u_{a} / \partial \theta+\left(\partial u_{a} / \partial \tau\right)_{\tau=\hat{\tau}}(d \hat{\tau} / d \theta)=\partial u_{a} / \partial \theta=$ $\hat{\tau} f(\tilde{l}(\hat{\tau}))-\xi\left(\theta \tilde{y}_{p}(\hat{\tau})\right) \tilde{y}_{p}(\hat{\tau})$. As $\theta \rightarrow \theta_{1}, d \hat{u}_{a} / d \theta \rightarrow-\tilde{y}_{p}(\bar{\tau})<0$, and as $\theta \rightarrow \theta_{2}, d \hat{u}_{a} / d \theta \rightarrow$ $\check{\tau} f(\tilde{l}(\check{\tau}))>0$. Further, consulting the proof of Proposition 3 and using $d \hat{\tau} / d \theta<0$, we can show that $d \hat{u}_{a} / d \theta$ is increasing for all $\theta \in\left(\theta_{1}, \theta_{2}\right)$. Therefore, there is $\bar{\theta}$ such that $d \hat{u}_{a} / d \theta<0$ for $\theta<\bar{\theta}, d \hat{u}_{a} / d \theta=0$ for $\theta=\bar{\theta}$, and $d \hat{u}_{a} / d \theta>0$ for $\theta>\bar{\theta}$.

Lastly, consider the range $\left(\theta_{2}, \infty\right)$. The reasoning is analogous to that for the range $\left(0, \theta_{1}\right)$, so only the outline will be presented. Fix $\theta>\theta_{2}$. There is $\check{\tau} \geq \check{\tau}$ such that $\theta \tilde{y}_{p}(\tau) \geq$ $g^{\prime}(0)$ for $\tau \leq \grave{\tau}$ and $\theta \tilde{y}_{p}(\tau)<g^{\prime}(0)$ for $\tau>\dot{\tau}$. We can show that for $\tau \in(\check{\tau}<\tau<\grave{\tau})$ and $\tau \in(\grave{\tau}, \bar{\tau}), d u_{a} / d \tau$ is well defined and negative. Since $u_{a}$ changes continuously as $\tau$ changes, this implies that $\hat{\tau}=\check{\tau}$ and, consequently, $\hat{n}=0$. Since this is true for all $\theta \in\left[0, \theta_{1}\right)$, from $(6)^{\prime}, d \hat{u}_{a} / d \theta=\tau f(\tilde{l}(\check{\tau}))>0$ for all $\theta \in\left(0, \theta_{1}\right)$.

The proposition follows from the above three-part characterization of $d \hat{u}_{a} / d \theta$. Q.E.D.

Thus more productive producers may or may not be good for the autocrat. Intuitively, if the (pre-policy) productivity of the producers is high enough, the tax revenue is large enough so that the autocrat's concern for the tax revenue outweighs his concern for the costs of hiring workers. Thus the autocrat is better off with a higher productivity of the producers, which leads to greater tax revenue and higher employment costs. On the other hand, if the (pre-policy) productivity of the producers is low enough, the tax revenue is small enough so that the autocrat's concern for the costs of hiring workers outweighs his concern for tax revenue. Consequently, the autocrat prefers a lower productivity of the producers, which leads to less tax revenue and lower employment costs. In this latter 
case, then the autocrat may choose non-tax policies that reduce the productivity of the producers.

Note that in choosing the non-tax policies $\theta$, the trade-off between the tax revenue and the employment costs depends on the functions $f$ and $h$, which determine the (pre-policy) productivity of the producers, on the one hand, and on the function $g$, which determines the productivity of the autocrat's production, on the other. The following proposition characterizes the effect of the productivity of the autocrat's production on his non-tax policy preferences.

Proposition 7. Given $f$ and $h$, let $g_{1}$ and $g_{2}$ be two government production functions, where $g_{1}^{\prime}(n)<g_{2}^{\prime}(n)$ for all $n$. Let $\bar{\theta}_{1}$ and $\bar{\theta}_{2}$ be the respective cut-off values of non-tax policies. Then $\bar{\theta}_{1}<\bar{\theta}_{2}$.

Proof: Let the variables subscripted with 1 correspond to $g_{1}$ and the variables subscripted with 2 correspond to $g_{2}$. From the proof of Proposition 5, $\xi_{1}\left(y_{p}\right)<\xi_{2}\left(y_{p}\right)$ for all $y_{p}$. From the proof of Proposition 6, we have $\dot{\theta}_{1}<\dot{\theta}_{2}$ and $\ddot{\theta}_{2}<\ddot{\theta}_{2}$. If $\bar{\theta}_{1} \leq \dot{\theta}_{2}, \bar{\theta}_{1}<\bar{\theta}_{2}$ since $\dot{\theta}_{1}<\bar{\theta}_{1}<\ddot{\theta}_{1}$ and $\dot{\theta}_{1}<\bar{\theta}_{1}<\ddot{\theta}_{1}$. If $\bar{\theta}_{1}>\dot{\theta}_{2}$, from Proposition 5 , we can show that under at $\theta=\bar{\theta}_{1}, \hat{\tau}_{1}<\hat{\tau}_{2}$. Further, from the proof of Proposition 6 , we have that at $\theta=\bar{\theta}_{1}$ and under each of $g_{i}, i=1,2, d \hat{u}_{a} / d \theta=\hat{\tau}_{i} f\left(\tilde{l}\left(\hat{\tau}_{i}\right)\right)-\xi_{i}\left(\check{\theta}_{1} \tilde{y}_{p}\left(\hat{\tau}_{i}\right)\right) \tilde{y}_{p}\left(\hat{\tau}_{i}\right)$. Using $\hat{\tau}_{1}<\hat{\tau}_{2}$ and $\xi_{1}<\xi_{2}$ and consulting Proposition 4, we can show that the righthand side of this equation decreases as $\xi_{1}$ and $\hat{\tau}_{1}$ change to $\xi_{2}$ and $\hat{\tau}_{2}$. Since $d \hat{u}_{a} / d \theta=0$ at $\bar{\theta}_{1}$ under $g_{1}, d \hat{u}_{a} / d \theta<0$ at $\bar{\theta}_{1}$ under $g_{2}$. Given this, consulting the proof of Proposition 6 once again, we can show that $\bar{\theta}_{1}<\bar{\theta}_{2}$. Q.E.D.

Thus, if the autocrat's production is more productive, it is more likely for him to prefer lower productivity of the producers. Intuitively, if his own production is more productive, the autocrat would employ more workers and his total wage payment would be higher. Consequently, he is more concerned about lowering the employment costs and thus more willing to choose policies to that effect. 


\section{Discussion}

The results of the analysis in Sections 2 and 3 can be summarized as follows. In an environment where an autocrat taxes producers and employs workers for his own production, the tax rate determines not only the producer's income but also the wage rate of the workers. A higher tax rate reduces the producer's income and, under free mobility of labor, this reduces the wage rate that the autocrat has to offer to his workers. Thus, an own-income-maximizing autocrat sets the tax rate above the revenue-maximizing rate. In other words, the chosen tax rate lies on the backward-bending part of the Laffer curve. The greater the productivity of the autocrat's production (relative to the productivity of producers) is, the higher the tax rate is. Further, the autocrat may want to repress the productivity of producers through non-tax policies. Again, the greater the productivity of the autocrat's production (relative to the policy-free productivity of producers) is, the greater the incentive for the autocrat to repress the productivity of producers is.

Let me note some of the essential and modifiable elements of the story. First, essential for the story is that the autocrat could supervise some but not all of the production in the economy. This may be because the autocrat cannot physically or time-wise supervise all of the production: as he supervises more, the effectiveness of supervision diminishes, analogous to the manager's limited 'span of control' in the theory of industrial organization. More importantly, there may be different types of production, some more supervisable than others. More supervisable production include military operations, plantation production, and mineral extraction. Less supervisable production include peasant farming and commerce. If the autocrat could easily supervise all of the production in the economy, there will be no private production, and consequently policy on private production would not be an issue. If the autocrat could not supervise any of the production, there will be no workers working for him, and consequently there would be no incentive for the autocrat to repress the income level of the private producers. Only when the autocrat could supervise 
some but not all of the production in the economy, would he supervise some production and tax the rest.

Second, in the story the autocrat can be replaced by a ruling class or an elite who can act as a unit to maximize the total income of the members. Essential for the story is the distinction between the ruling class and its workers. In an analogy with the operation of a firm, the distinction is between the shareholders and the employees: the shareholders collectively want to maximize their return by, among the various means, minimizing the wage payment to the employees. Thus, military leaders and high-level bureaucrats would belong to the ruling class. Rank-and-file soldiers and minor bureaucrats would not. Third, the wage rate of the autocrat's workers do not need to be the same as the income of the producer. The autocrat may want to pay more, for example, as a way of boosting loyalty. As a result, the autocrat's workers may command a higher income level than the producers. Essential for the story is that, regardless of the size of this premium, the autocrat can reduce the wage rate of his workers by reducing the opportunity cost of working for him, that is, the income level of the producers.

I do not have direct evidence that the incentive to repress the income level of producers modeled in this paper is important in policy making in the autocratic regimes. However, the kind of environment that the story requires and the kind of outcome that the story tells can be observed in various countries. The militaristic regimes of the Ottoman empire and the Indian Mughal empire were conquerors from Central Asia, and had little interest in the welfare of the local populations. Speaking of the Ottoman empire, Inalcik (1969) states, "all classes of society and all sources of wealth were regarded as obliged to preserve and promote the power of the ruler. ... The populace was regarded as forming two main groups-those who represented the ruler's authority (the administrators, the troops, the men of religion), and the ordinary subjects; the former were not concerned with production and paid no taxes, while the latter were the producers and the tax-payers." Note that the two groups of population that Inalcik distinguishes are exclusive of the ruler. Citing Moorland 
(1972), Jones (1987) talks about "parasites and policemen" in the Mughal Empire, who lived off producers. He goes on to say, "Since most parasites lived no better than the peasants, a very large proportion of total income was being shared among a tiny elite of non-producers." Thus it appears that in these empires, there were three groups of people, a tiny ruling class, people employed by the ruling class for various reasons, and the rest of the population, and the second group was only marginally better off than the third. The size of the second group may have been quite large. For the Mughal empire, Habib (1969) suggests soldiers numbering over 20 million in 1595 out of a population on the order of 100 million. He also mentions that some members of the ruling class were also engaged in khud-kasht mode of production, a large-scale cultivation of cash crops using hired labor. This mode of production encroached upon peasant production, but its expansion was constrained by the limits of supervision and of applicability for non-cash crops. Given that the ruling class employed a sizable number of people, it may have had an incentive to reduce the wage payment by repressing the income level of the producers. And the policy was repressive in these empires. Habib (1969) suggests a tax rate of more than $50 \%^{1}$ for peasant production in the Mughal empire. Jones (1987) states that "The Ottoman empire ... operate[d] an economic system that rested on confiscation, despoilment, and a total, calculated, insecurity of life and property," and in the Mughal Empire "Escape from impoverishment 'was barred effectively by the administrative methods ... which ... regarded every indication of increased consumption as a signal for fresh extortion' (Moreland 1972)."

Turning to more recent examples, the autocratic regimes of Trujillo in the Dominican Republic (1930-1961) and Mobutu in Zaire (1965-1997) were willing to enrich a narrow circle of people at the expense of the rest of the population. Sugar production from

1 Here the tax includes 'land revenue, other dues and claims by superiors.' It is not clear whether this includes rent. Even if it did, the size of rent was only 10 to $25 \%$ of the size of the land revenue, which is exclusive of the rent. 
sugarcane, an excellent example of a large scale plantation crop, is a major sector in the Dominican Republic. Trujillo's primary means of enrichment was sugar production. He seized a large portion of land by forcing peasants off their land, and increased sugarcane production. He also owned the most of sugar mills. The majority of rural Dominicans owned little land and relied on wage labor, and sugar production was a major source of work for them. In this situation, Trujillo may have wanted to lower the wage rate by repressing the peasant farming and other private production. Not inconsistent with this motivation, he neglected agriculture other than sugar production. The peasant production was much less modernized and much less productive than most of the other Latin American countries. In Zaire, the mining and processing of copper, diamonds, and other minerals is a major sector of the economy, and it was a major source of enrichment for Mobutu's regime. Notably, when Mobutu came to power, he turned the giant mining firm UMHK into the parastatal Gecamines, whose profits were subsequently diverted to the regime. Again, not inconsistent with the story in this paper, his policy toward private production was very poor. For instance, toward the end of his regime, "by some estimates, as little as 10 percent of the road network in existence at independence was still functioning" (Medits and Merrill 1993). Due to his policy, under his regime the agricultural sector deteriorated to the point of having to import food, and the informal sector ballooned to be three times as large as the formal sector.

The above examples of regimes that repressed the private sector can be contrasted with other more moderate regimes. Relative to the Ottman and Muhgal empires, China and European countries were more friendly toward private producers. Feuerwerker (1984) estimate the tax revenue as a percentage of national income to be 5 to $13 \%$ during Song, Ming, and Qing dynasties, and suggests that this is comparable to preindustrial Europe. Perkins (1967) takes the view that the Chinese government was not a hindrance for industrialization in the 19th century although neither did it promote industrialization. Of course, industrialization did take place first in Europe, largely driven by the private sector. 
It is notable that, except for brief periods of foreign domination, China was not as militaristic as the Ottoman and Mughal empires. Neither was Europe. This is consistent with the story in this paper: with less need for military recruitment, there is less need for selfish autocrats to repress the private producers. ${ }^{2}$ In the more recent past, Lee Kuan Yu's regime in Singapore (1959-1989) and Park Jung Hee's in South Korea (1961-1979) implemented policy that promoted the private sector, in sharp contrast to the regimes of Trujillo and Mobutu. It is notable that Singapore and South Korea neither have a plantation economy like the Dominican Republic nor have large mineral resources as in Zaire. This is again consistent with the story in this paper: with no need for recruiting workers for plantations or mines, there is less need for autocrats to repress the private sector.

\section{CONCLUSION}

In this paper, I proposed a reason why an autocratic regime may implement policies that are harmful to private producers, such as excessive taxation, confiscation, and neglect of public goods. The basic idea is that if the autocrat engages in his own production, bad policies can benefit him by lowering the income level of the population and thereby reducing the wage payment for his workers. The story is helpful in understanding bad policies that were present in militaristic regimes of the Ottoman and Mughal empires, Trujillo's regime in the plantation-based economy of the Dominican Republic, and Mobutu's regime in mineral-rich Zaire. In all of these examples, the autocrats enjoyed long tenure, spanning decades or more, and seem to have been secure in power. Therefore, explanations based on short tenure seem inapplicable. Another reason for bad policies under long-tenured

2 16th and 17th century Spain provides perhaps the most militaristic regime in Europe. It had a huge army and its policy toward private producers was notably oppressive (see Elliott (1961) and North and Thomas (1973)). England, during its imperial era, had a less autocratic regime than the Ottoman and Mughal empires. The European country that is the most unfavorable to the story in this paper may be Prussia under Frederick William I to Frederick the Great. It had a large army but the autocrats promoted economic growth in general, although much of this growth was driven by the state rather than the private sector (see Anderson (1974) for example). 
autocrats may be that bad policies are somehow helpful in extending tenure, as proposed by Robinson (1997b). I consider the story in this paper to be a complement to rather than a substitute for Robinson's. 


\section{REFERENCES}

Anderson, P. (1974), Lineages of the Absolutist State, Verso Edition 1979, Verso Editions, London.

Buchanan, J. and Lee, D. (1982) "Politics, Time, and the Laffer Curve," Journal of Political Economy 90(4):816-19.

Elliott, J. (1961) "The Decline of Spain," Past and Present 20:52-75.

Feuerwerker, D. (1984), "The State and the Economy in Late Imperial China," Theory and Society 13:297-326.

Habib, I. (1969) "Potentialities of Capitalistic Development in the Economy of Mughal India," Journal of Economic History 29(1):32-78.

Haggerty, R. (1989), ed., Dominican Republic: A Country Study, Federal Research Division, Library of Congress. (Available at http://lcweb2.loc.gov/frd/cs)

Harden, B. (1993), Chapter 1 in Africa: Dispatches from a Fragile Continent, HarperCollins, London.

Inalcik, H. (1969) "Capital Formation in the Ottoman Empire," Journal of Economic History 29:97-140.

Jones, E. (1987), The European Miracle: Environments, Economies, and Geopolitics in the History of Europe and Asia, Second Edition, Cambridge University Press.

Kabwit, G. (1979) "Zaire: the Roots of the Continuing Crisis," Journal of Modern African Studies 17:381-407.

Lenski, G. (1966), Power and Privilege: a Theory of Social Stratification, Paperback Edition 1984, The University of North Carolina Press.

Lundahl, M. and Vedovato, C. (1989) "The State and Economic Development in Haiti and the Dominican Republic," Scandinavian Economic History Review 37:39-59.

Medits, S. and Merrill, T. (1993), ed., Zaire: A Country Study, Federal Research Division, Library of Congress. (Available at http://lcweb2.loc.gov/frd/cs)

Moreland, W. (1923), From Akbar to Aurangzeb, Reprint 1972, Oriental Books Reprint Co., New Delhi.

North, D. and Thomas, R. (1973), The Rise of the Western World, Cambridge University Press.

Perkins, D. (1967), "Government as an Obstacle to Industrialization: the Case of Nineteenth-Century China," Journal of Economic History 27:478-92.

Robinson, J. (1997a), "A Political Theory of Underdevelopment," Manuscript, Department of Economics, University of Southern California.

Robinson, J. (1997b), "When is a State Predatory," Manuscript, Department of Economics, University of Southern California. 